\title{
Em tempos de pandemia pela COVID-19: o desafio para a educação em saúde
}

\section{In times of pandemic by COVID-19: the challenge for health education}

\section{Maria Augusta \\ Vasconcelos Palácio*}

lukary Takenami
Universidade Federal do Vale do São Francisco (UNIVASF), Paulo Afonso, BA, Brasil

\footnotetext{
* E-mail: augusta.palacio@univasf.edu.br
}

\begin{abstract}
RESUMO
Trata-se de um ensaio que busca refletir sobre os desafios e as perspectivas de educar em saúde frente a pandemia da doença causada pelo novo coronavírus, COVID-19. Com base na reflexão sobre o atual cenário, são apontadas algumas dificuldades encontradas por autoridades e profissionais de saúde que estão na linha de frente da educação da população para seguir as recomendações dos órgãos oficiais de saúde. As clássicas formas de prevenção, de grande importância para a saúde pública, como o isolamento social e a adoção de bons hábitos de higiene da população, ainda encontram barreiras para serem implementadas.
\end{abstract}

PALAVRAS-CHAVE: COVID-19; Pandemia; Educação em Saúde

\begin{abstract}
This is an essay that seeks to reflect on the challenges and perspectives of health education in the face of the pandemic caused by the new coronavirus, COVID-19. Based on the reflection on the current scenario, some difficulties are pointed out by authorities and health professionals who are at the forefront on the education of the population to follow the recommendations of official health agencies. The classic forms of prevention, of great importance for public health, such as isolation and the adoption of hygiene habits by the population, still face barriers to be implemented.
\end{abstract}

KEYWORDS: COVID-19; Pandemic; Health Education 


\section{INTRODUÇÃOO}

Diante da pandemia da doença causada pelo novo coronavírus, COVID-19, surgem inquietações daqueles que pesquisam e atuam nos campos da saúde e da educação sobre um dos maiores desafios da prática do profissional de saúde - a educação em saúde. 0 cenário é de preocupação não apenas pelo avanço do vírus, mas pela dificuldade de adoção de medidas simples de cuidado em saúde, principalmente, aquelas relacionadas à prevenção e ao combate à doença. Essas medidas, consideradas clássicas na saúde pública, como o isolamento e a quarentena, foram amplamente utilizadas desde o século XIV e até meados do século XIX. A abrangência e o impacto dessas medidas influenciaram significativamente o curso de epidemias como: varíola, peste bubônica e gripe espanhola'.

Naquela época, não existia o arcabouço tecnológico e científico disponível na atualidade. As políticas de saúde pública visavam apenas interferir no meio ambiente e no controle da transmissão das doenças. As equipes de saúde eram constituídas, majoritariamente, por agentes sanitários e poucos médicos ${ }^{2}$. Somente na década de 1920 , os fatores sociais que interferem nas condições de saúde da coletividade passaram a ser abordados nos serviços de saúde pública, com ações de vigilância sanitária, assim como a divulgação da importância da higiene individual e a incorporação do médico como profissional do serviço de saúde ${ }^{2,3}$.

Até o final do século XIX, os agentes biológicos, causadores das epidemias, eram desconhecidos. Curiosamente, quando a pandemia da gripe espanhola acabou, foram precisos mais 13 anos para que os pesquisadores encontrassem a causa, um vírus conhecido como Influenza $A^{4}$. Por outro lado, o avanço científico e tecnológico permitiu ao mundo conhecer em poucas semanas o agente etiológico da COVID-19, o coronavírus da síndrome respiratória

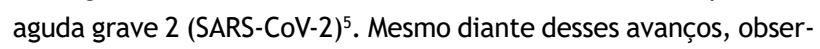
vam-se grandes dificuldades em transpor, de forma apropriada, as medidas clássicas de saúde pública para um mundo globalizado.

Amplamente divulgadas, as recomendações dos órgãos de saúde para conter o avanço da epidemia no Brasil têm enfrentado resistência e revelado muitos limites e desafios para profissionais de saúde, sobretudo em relação às práticas de educação em saúde. Essas ainda se encontram fortemente marcadas por concepções tradicionais e verticalizadas, e têm se revelado de forma pontual e fragmentada nas ações de assistência e vigilância à saúde. Ademais, a massiva veiculação de informações falsas ou divergentes daquelas oficiais tem comprometido a adesão da população às recomendações de prevenção à COVID-19.

Muitas pessoas recebem informações e orientações, acompanham a rápida expansão da doença pelo mundo, mas mostram-se pouco receptivas às recomendações que chegam até elas. Educar é tão difícil assim? Ou os meios de comunicação não são efetivos? Como explicar a necessidade de medidas mais radicais serem impostas para que as pessoas entendam que é preciso cautela, prevenção e vigilância? Onde está o erro? Ou o que se precisa fazer para mudar essa situação? Diante do não cumprimento voluntário por interesses incompatíveis com o bem-estar da população, muitos órgãos municipais se viram obrigados a impor em seus territórios ações fiscais e administrativas para proteger a população de um risco sanitário. Assim, nas últimas semanas, a divulgação de decretos municipais por todo território nacional, determinando o fechamento temporário de estabelecimentos não essenciais, o uso obrigatório de equipamentos de proteção individual como máscaras, luvas, higienização do ambiente em serviços essenciais e a implantação de barreiras de controle sanitário nas entradas e saídas dos municípios foram algumas das medidas implementadas para que a população permaneça em distanciamento social, medida essencial para contenção do SARS-CoV-2.

A compreensão sobre a educação em saúde aqui tecida nasce do entendimento proposto por Schall e Struchiner ${ }^{6}$, ao defini-la como um campo multifacetado, formado por distintas concepções oriundas tanto da área da saúde quanto da educação ${ }^{6}$. A saúde, sobretudo no âmbito da sua promoção, não se faz sem a educação, sem os princípios teóricos e metodológicos que orientam esse campo. Talvez esse seja o maior desafio, promover esse diálogo, compreendendo também que todo esse processo requer a participação do indivíduo e maior compreensão sobre o seu contexto de vida.

Acrescenta-se a esse conceito a reflexão proposta por Parreira ${ }^{7}$, ao discutir os caminhos e percursos necessários à educação em saúde. Para a autora, o profissional de saúde tem recebido o desafio de mediar processos, atuar na mobilização de grupos e no diálogo com segmentos populacionais de diferentes culturas que possuem expectativas diferentes em relação a si - sua saúde e aos serviços de saúde. Por sua vez, demanda dos profissionais de saúde, habilidades e atitudes para a ação educativa em seu processo de trabalho ${ }^{7}$, o que nem sempre é possível devido à pressão assistencial elevada.

As práticas educativas precisam englobar o conhecimento de ambos os lados - saúde e educação - para que as ações de cuidado sejam exitosas - aqui inclui prevenção, proteção, promoção, reabilitação, cuidados paliativos e não apenas a cura de doenças. Contudo, esse êxito apenas será alcançado quando se assume o entendimento de que educar em saúde requer práticas dialógicas, inovadoras e que defendam a "busca pela democratização não somente das informações, mas dos saberes, e das diferentes culturas"7. Quais os desafios enfrentados diante da pandemia da COVID-19 no contexto das práticas de educação em saúde? Embora as práticas de educação em saúde façam parte do processo de trabalho de profissionais da Atenção Primária à Saúde (APS), da atenção especializada e da vigilância em saúde, tendem a ser relegadas a um segundo plano, por quê?

Um novo vírus e "velhos" desafios para a saúde pública

A nova variante do coronavírus, SARS-CoV-2, foi identificada pela primeira vez em dezembro de 2019, em Wuhan, província de Hubei, China. 0 vírus se espalhou para outras regiões da China e, rapidamente, avançou para diferentes países e territórios. Dados divulgados em 04 de abril de 2020 pela Johns Hopkins 
University mostram que já são 1.196.553 infectados, 64.549 óbitos e 181 países atingidos ${ }^{8}$. No Brasil, nesta mesma data, foram confirmados 10.278 casos e 431 óbitos. Há notificações de casos confirmados de infecção pelo SARS-CoV-2 em todos os estados e no Distrito Federal ${ }^{8}$.

A transmissão do vírus ocorre, principalmente, por gotículas, secreções respiratórias ou contato direto com o indivíduo infectado 9 . 0 período de incubação pode variar de quatro a 14 dias. Após esse período, surgem os primeiros sinais e sintomas relacionados à síndrome respiratória aguda grave, como: febre, tosse seca, dor de garganta e, em alguns casos, insuficiência respiratória. O diagnóstico da infecção pelo SARS-CoV-2 baseia-se na detecção do ácido nucleico viral por meio de uma reação em cadeia da polimerase com transcrição reversa e amplificação em tempo real (RT-qPCR) ${ }^{10,11}$. Mais recentemente, com o objetivo de acelerar a detecção dos indivíduos infectados e quebrar o ciclo de transmissão da doença, o governo brasileiro anunciou a compra de testes rápidos (imunocromatografia). 0 tratamento é basicamente suporte clínico por meio da hidratação, repouso, uso de antitérmicos e, eventualmente, suplementação de oxigênio ou ventilação mecânica ${ }^{11}$. Assim, o diagnóstico precoce e a imposição de barreiras sanitárias são importantes estratégias para conter os avanços da COVID-19, uma vez que não há medicamentos específicos para o tratamento da doença.

O avanço do vírus a nível mundial estimulou os governos a recorrerem às tradicionais medidas de saúde pública, como: higiene, isolamento, quarentena, distanciamento social, restrição do tráfego aéreo e transportes terrestres, com o fechamento de fronteiras em muitos países ${ }^{9,12,13}$. Essas ações são direcionadas à prevenção da infecção e à mitigação da disseminação do vírus, em uma corrida contra o tempo na busca por respostas em relação ao tratamento das pessoas infectadas, pelo desenvolvimento de uma vacina e pela prevenção de um colapso dos sistemas de saúde.

Diferentemente dos séculos passados, a saúde pública possui, atualmente, importantes aliadas no combate à COVID-19. As tecnologias digitais de informação e comunicação (TDIC) podem contribuir para minimizar o impacto da disseminação, permitindo um maior alcance das práticas de educação em saúde. As tecnologias da era digital têm exercido um papel fundamental na divulgação de informações pertinentes à doença, como: orientação da população sobre dados epidemiológicos, avanços e perspectivas na ciência, medidas de prevenção e controle, ajuda psicológica e especializada. Todas essas informações são amplamente divulgadas nas mídias sociais por meio de vídeos, estudos científicos, animações, simulações, aplicativos de monitoramento e informações compartilhadas em grupos de aplicativos de mensagens. A COVID-19 é a primeira grande pandemia da era das mídias sociais, o que tem promovido oportunidades para a rápida distribuição de informações em tempo real, e isso fortalece a cooperação humanitária no combate à afecção ${ }^{14}$.

Embora as TDIC sejam indispensáveis nesse momento e contribuam para práticas inovadoras em educação em saúde, principalmente em tempos de isolamento, quarentena e distanciamento social, podem também ser uma poderosa ferramenta na divulgação de informações duvidosas e não confiáveis. Assim, paralelamente à pandemia da COVID-19, a Organização Mundial da Saúde (OMS) tem enfrentado outra epidemia que tem mudado a forma como os indivíduos se relacionam com a saúde, descredibilizando os esforços da ciência na luta contra a COVID-19. Esse movimento de disseminação de notícias falsas, também conhecido como fake news ou movimento "anticiência", apenas prejudica o trabalho dos profissionais, pesquisadores e gestores de saúde. É bem verdade que as mídias sociais são grandes aliadas na propagação de informações sobre medidas de prevenção e dados sobre a distribuição de casos. Contudo, têm o poder de disseminar notícias falsas, na mesma proporção ${ }^{15,16}$. Neste momento de pandemia, o pânico e o medo têm se espalhado globalmente nas mídias sociais, muito mais rápido que o vírus ${ }^{15}$.

De acordo com Mian e Khan ${ }^{16}$, informações básicas sobre formas de transmissão e prevenção podem ser desacreditadas por algumas fontes não oficiais ${ }^{16}$. Algumas informações que prometem a cura do vírus com remédios caseiros, como comer alho e tomar vitamina C, estão entre as medidas mais veiculadas, mesmo sem nenhuma evidência científica. Informações como essas podem gerar confusão na população e um descrédito em relação às orientações dos órgãos de saúde, levando a uma maior propagação do vírus ${ }^{16}$. Esse cenário contribui ainda mais para a ineficiência das práticas de educação em saúde.

A pandemia da COVID-19 tem revelado outra dimensão na qual a educação em saúde requer estratégias diversas para alcançar seu objetivo, dentre elas, as crenças pessoais, a visão de mundo amplamente influenciada por fatores históricos, culturais e sociais, que irão determinar as escolhas dos indivíduos.

Estudo realizado por Lima et al. ${ }^{17}$ sobre aspectos comportamentais, valores e crenças da população cearense frente a pandemia da COVID-19 mostrou que alguns grupos estão mais vulneráveis à infecção, dentre eles: homens, indivíduos com baixa escolaridade, idosos a partir de 80 anos e aqueles residentes em municípios localizados do interior do estado. Esse resultado é reflexo, em grande parte, da minimização da propagação do vírus e do descumprimento de medidas recomendadas pelas autoridades sanitárias. Os idosos entrevistados estão cumprindo parcialmente a quarentena, acreditam que a pandemia não é uma ameaça "real" e que o clima cearense favorecerá a diminuição de casos da COVID-19. Curiosamente, os indivíduos que residem no interior do estado e/ou que possuem o ensino fundamental concluído também compartilham o mesmo pensamento. Ademais, verifica-se que o gênero masculino está associado à não realização voluntária da quarentena ${ }^{17}$.

Dessa forma, observa-se que muitos fatores influenciam a resposta dos indivíduos às práticas de educação em saúde e que estas podem causar conflitos e divergências nos saberes e nas práticas de saúde. Assim, a compreensão sobre a visão de mundo dos indivíduos, as crenças, os aspectos sociais, familiares e culturais podem representar um grande desafio para os profissionais que estão diretamente envolvidos no enfrentamento à pandemia pelo SARS-CoV-2, seja nas práticas de cuidado, de vigilância, no planejamento e na gestão em saúde. 


\section{Educação em saúde - o desafio em transpor a teoria}

As discussões sobre o conceito de educação em saúde convidam à reflexão sobre como alcançar um "ideal teórico" que possa se materializar em "práticas concretas" nos mais variados contextos de atuação dos profissionais de saúde, desde a APS, espaço singular para aprofundar as ações de educação em saúde e trabalhar cotidianamente as relações de afeto e de cuidado necessárias ao processo educativo, até os níveis de atenção que oferecem uma maior densidade tecnológica. Não há um espaço único para que a educação em saúde seja realizada, pois ela requer encontros entre os sujeitos e esses podem acontecer em todos os lugares.

De acordo com Schall e Struchiner ${ }^{6}$, a educação em saúde, no Brasil, compreende a aprendizagem sobre as doenças e como preveni-las, bem como seus efeitos sobre a saúde. Por outro lado, está fortemente atrelada ao conceito de promoção da saúde, proposto pela OMS. Esse conceito reflete no empoderamento da população. "É a capacitação da comunidade para atuar na melhoria da sua qualidade de vida e saúde"18, é oferecer os meios (informações e recursos necessários) para que ela possa se prevenir, cuidar da família, do ambiente, da sua comunidade e alcançar saúde, no seu sentido positivo, e qualidade de vida.

Para além desse entendimento, a educação em saúde é compreendida como um

processo político pedagógico que requer o desenvolvimento de um pensar crítico e reflexivo que desperte no indivíduo a sua autonomia e emancipação enquanto sujeito histórico e social capaz de propor e opinar nas decisões de saúde para o cuidar de si, de sua família e da coletividade ${ }^{19}$.

Contudo, em um cenário de tantas incompreensões, como ensinar o outro a pensar criticamente e de forma reflexiva? Como despertar nele a sua autonomia e emancipação? Como ele pode transformar esse conhecimento em decisões corretas para cuidar de si e do coletivo?

Chega-se a outro ponto dessa reflexão. O envolvimento do coletivo e não apenas do individual nas práticas de cuidado em saúde. Este é o cenário que a pandemia da COVID-19 tem revelado: a dificuldade de envolver o coletivo ou uma parcela dele na adoção de medidas, como a quarentena e o distanciamento social, que, apesar de validadas pelos órgãos de saúde, não têm encontrado tanta adesão, proporcionando maior disseminação do vírus.

No escopo desses desafios à educação em saúde, resgata-se um histórico de intervenções educativas pontuais, restritas aos programas de saúde no âmbito de APS, com pouca articulação aos outros programas e setores, a exemplo da vigilância sanitária, conforme destaca Lucena: "A vigilância sanitária herdou uma tradição normatizadora e cartorial em seu processo de trabalho que, por vezes, dificulta a adoção de abordagens educacionais abertas e inovadoras" ${ }^{20}$. Como saída, a autora salienta que, embora a vigilância sanitária precise incorporar o saber popular para superar o informe vertical sobre riscos, a adoção de práticas inovadoras, pautadas em metodologias ativas de aprendizagem, dialógicas e promotoras de autonomia tem demonstrado avanços nas abordagens de educação em saúde na vigilância sanitária ${ }^{20}$.

As mesmas recomendações, por repetidas vezes, trabalhadas em práticas de educação em saúde em unidades de saúde, escolas, unidades produtoras e comercializadoras de alimentos - orientações sobre higienização das mãos e de alimentos, uso de equipamentos de proteção individual, como máscaras e luvas - já deveriam ser práticas recorrentes, garantindo melhores condições de saúde e bem-estar individual e coletivo. No caso da saúde, na prática, o que tem sido avaliado é que a manutenção de hábitos e comportamentos inadequados tornam os ambientes de atenção à saúde, locais inseguros, tanto para os trabalhadores como para os pacientes e seus respectivos acompanhantes ${ }^{21,22}$.

Outro desafio que deveria ser considerado é o alcance que as mídias sociais proporcionam, no que se refere ao rápido e fácil acesso às informações. Já que essas mídias se tornaram um dos caminhos, talvez o mais predominante, de acesso às informações, cabe à saúde pública encontrar melhores estratégias para se comunicar sobre os planos de mitigação da COVID-19 por meio delas ${ }^{14}$. Os indivíduos passaram a participar de forma ativa e a ter uma maior autonomia na busca do conhecimento. Por outro lado, em um país com um perfil demográfico e cultural diverso, o acesso à internet e às mídias sociais para toda a população ainda não é uma realidade.

Nesse sentido, questionamentos emergem nessa discussão: como promover educação em saúde a grupos populacionais que não possuem acesso à internet? Como fazer chegar a informação cientificamente validada à toda população? É possível aliar as tecnologias às práticas de educação em saúde para conhecer o outro, sua realidade? Identificar, na comunidade, indivíduos que possam ajudar nesse processo de educação, a partir da construção de redes de colaboração? Cabe aqui refletir sobre algumas saídas para esse problema no combate à COVID-19.

Nesse cenário de pandemia, outras estratégias educativas têm sido utilizadas, como o papel da vigilância em saúde nas barreiras sanitárias, tentando levar orientações a um maior número de indivíduos, e as já mencionadas, veiculadas por diferentes TDIC. No entanto, vale lembrar que "não se aprende por acumulação ou por motivos utilitários, mas por ganho de significado e de sentido"7. Aprende-se, sobretudo, pelo compartilhamento de experiências e práticas intermediado pela construção de um pensamento crítico e reflexivo.

As estratégias de educação em saúde precisam estar ancoradas em propostas pedagógicas libertadoras ${ }^{6}$, que sejam construídas a partir de um maior conhecimento do contorno geográfico, social, político, cultural do indivíduo, família e comunidade ${ }^{19}$. Esse pensamento recorre aos ideais freirianos, da necessidade de conhecer a realidade do outro - sujeito das práticas de saúde, e de autores que também defendem a aprendizagem pela experiência, como John Dewey (1859-1952) e Celèstin Freinet (1896-1966). Desta forma, deve-se conhecer o outro e valorizar seus saberes, procurar meios que não sejam apenas reflexo de práticas reducionistas, impositivas e pontuais. 
Educação não se constrói da noite para o dia. É um processo e, como tal, requer a busca pelos melhores caminhos. 0 compartilhamento de experiências inovadoras nascidas nas salas de aula e em campos de práticas na área da saúde, em projetos de extensão e na pesquisa científica representa importante estratégia para agregar conhecimento e ampliar o olhar para as possibilidades de fazer educação em saúde com o outro. Entende-se que este momento é propício a se repensar as práticas de educação em saúde e valorizá-las, cotidianamente, nos serviços de saúde, nos diferentes níveis de atenção, como estratégia transversal à prática de todos os profissionais envolvidos no cuidado em saúde.

\section{CONCLUSÕES}

Para não concluir...

A pandemia da COVID-19 tem acendido o alerta sobre diversas situações para as quais o mundo não estava preparado. Um novo vírus, sem tratamento ainda comprovado, nem vacina para sua prevenção. Trouxe também um alerta sobre os baixos investimentos em saúde, pois mesmo países desenvolvidos têm enfrentado a falta de insumos básicos, como equipamentos de proteção individual para profissionais de saúde. Além dos impactos sociais e econômicos que medidas como o distanciamento social, o fechamento de fronteiras e a proibição de funcionamento de serviços não essenciais, comércio e alguns setores da indústria, por exemplo, têm causado. E permeando todo esse cenário, a dificuldade encontrada por autoridades de saúde e profissionais que estão na linha de frente da educação da população para seguir as recomendações dos órgãos oficiais de saúde. As "clássicas formas" de prevenção, de grande importância para a saúde pública, relacionadas aos hábitos de higiene da população ainda encontram barreiras para serem implementadas. Soma-se a isso, a divulgação de notícias falsas, principalmente, nas redes sociais e certo descrédito em relação ao que o mundo está vivendo. Diante de tantos problemas e incertezas, acredita-se que esse tenha sido um dos maiores desafios atuais: educar em saúde.

\section{REFERÊNCIAS}

1. Teixeira MG, Costa MCN, Carmo EH, Oliveira WK, Penna GO. Vigilância em saúde no SUS: construção, efeitos e perspectivas. Cienc Saude Coletiva. 2018;23(6):1811-8. https: / / doi.org/10.1590/1413-81232018236.09032018

2. Ferreira JBB, Forster AC. Epidemiologia e políticas de saúde. In: Passos ADC, Franco LJ, organizadores. Fundamentos de epidemiologia. Barueri: Manole; 2011. p. 319-37.

3. Merhy EE. $O$ capitalismo e a saúde pública: a emergência das práticas sanitárias no estado de São Paulo. Campinas: Papirus; 1987.

4. Goulart AC. Revisitando a espanhola: a gripe pandêmica de 1918 no Rio de Janeiro. Hist Cienc Saude-Manguinhos. 2005;12(1):101-42. https://doi.org/10.1590/S0104-59702005000100006

5. Zhu Z, Zhang D, Wang W, Li X, Yang B, Song J et al. Novel coronavirus from patients with pneumonia in China, 2019. N Engl J Med. 2020;382(8):727-33. https://doi.org/10.1056/NEJMoa2001017

6. Schall V, Struchiner M. Educação em saúde: novas perspectivas. Cad Saude Publica. 1999;15(supl 2):s4-6. https://doi.org/10.1590/S0102-311X1999000600001

7. Parreira CMFS. Educação em saúde: caminhos e percursos para uma vida saudável. In: Lacerda E, Hexsel R, organizadores. Educação em vigilância sanitária. Brasília: Agência Nacional de Vigilância Sanitária; 2018. p. 18-25.

8. Johns Hopkins University - JHU. Covid-19 dashboard by the center for systems science and engineering (CSSE) at Johns Hopkins university (JHU). Baltimore: Johns Hopkins University; 2020[acesso 5 abr 2020]. Disponível em: https://coronavirus.jhu.edu/map.html

9. Lake MA. What we know so far: Covid-19 current clinical knowledge and research. Clin Med. 2020;20(2):124-7. https://doi.org/10.7861/clinmed.2019-coron
10. Guan WJ, Ni ZY, Hu Y, Liang WH, Ou CQ, He JX et al. Clinical characteristics of coronavirus disease 2019 in China. N Engl J Med. 2020:1-13. https://doi.org/10.1016/j.jinf.2020.03.041

11. Jin YH, Cai L, Cheng ZS, Cheng H, Deng T, Fan YP et al. A rapid advice guideline for the diagnosis and treatment of 2019 novel coronavirus (2019-nCoV) infected pneumonia. Mil Med Res. 2020;(7):1-23. https://doi.org/10.1186/s40779-020-0233-6

12. Wilder-Smith A, Freedman DO. Isolation, quarantine, social distancing and community containment: pivotal role for old-style public health measures in the novel coronavirus (2019-nCoV) outbreak. J Travel Med. 2020;27(2):1-4. https://doi.org/10.1093/jtm/taaa020

13. Pan X, Ojcius DM, Gao T, Li Z, Pan C, Pan C. Lessons learned from the 2019-nCoV epidemic on prevention of future infectious diseases. Microbes Infect. 2020;22(2):86-91. https://doi.org/10.1016/j.micinf.2020.02.004

14. Guest JL, Del Rio C, Sanchez T. The three steps needed to end the Covid-19 pandemic: bold public health leadership, rapid innovations, and courageous political will. JMIR Public Health Surveill. 2020;6(2):1-4. https: //doi.org/10.2196/19043

15. Boulos MNK, Geraghty EM. Geographical tracking and mapping of coronavirus disease Covid-19 severe acute respiratory syndrome coronavirus 2 (SARS-CoV-2) epidemic and associated events around the world: how 21st century GIS technologies are supporting the global fight against outbreaks and epidemics. Int J Health Geogr. 2020;19(1):1-12. https://doi.org/10.1186/s12942-020-00202-8

16. Mian A, Khan S. Coronavirus: the spread of misinformation. BMC Med. 2020;18(1):1-2. https://doi.org/10.1186/s12916-020-01556-3 
17. Lima DLF, Dias AA, Rabelo RS, Cruz ID, Costa SC, Nigri FMN et al. Covid-19 no estado do Ceará: comportamentos e crenças na chegada da pandemia. Cien Saude Colet. 2020[acesso 10 abr 2020]. Disponível em: http://www.cienciaesaudecoletiva. com.br/artigos/covid19-no-estado-do-ceara-comportamentose-crencas-na-chegada-da-pandemia/17540?id=17540

18. Ministério da Saúde (BR). As cartas de promoção à saúde. Brasília: Ministério da Saúde; 2002[acesso 4 abr 2020]. Disponível em: https://bvsms.saude.gov.br/bvs/ publicacoes/cartas_promocao.pdf

19. Machado MFAS, Monteiro EMLM, Queiroz DT, Vieira NFC, Barroso MGT. Integralidade, formação de saúde, educação em saúde e as propostas do SUS: uma revisão conceitual. Cienc Saude Coletiva. 2007;12(2),335-42. https://doi.org/10.1590/S1413-81232007000200009
20. Lucena RCB. Educanvisa: considerações para análise no contexto da política de saúde brasileira. In: Lacerda $E$, Hexsel R, organizadores. Educação em vigilância sanitária. Brasília: Agência Nacional de Vigilância Sanitária; 2018. p. 54-8.

21. Mota EC, Barbosa DA, Silveira BRM, Rabelo TA, Silva NM, Silva PLN et al. Higienização das mãos: uma avaliação da adesão e da prática dos profissionais de saúde no controle das infecções hospitalares. Rev Epidemiol Control Infect. 2014;4(1):12-7. https://doi.org/10.17058/reci.v4i1.4052

22. Gomes AC, Carvalho PO, Lima ETA, Gomes ET, Valença MP, Cavalcanti AA. Caracterização das infecções relacionadas à assistência à saúde em unidade de terapia intensiva. Rev Enferm UFPE. 2014;8(6):1577-85. https://doi.org/10.5205/reuol.5876-50610-1-SM.0806201417

Contribuição dos Autores

Palácio MAV, Takenami I - Concepção, planejamento (desenho do estudo), aquisição, análise, interpretação dos dados e redação do trabalho. As autoras aprovaram a versão final do trabalho.

Conflito de Interesse

Os autores informam não haver qualquer potencial conflito de interesse com pares e instituições, políticos ou financeiros deste estudo.

Esta publicação está sob a licença Creative Commons Atribuição 3.0 não Adaptada.

Para ver uma cópia desta licença, visite http://creativecommons.org/licenses/by/3.0/deed.pt_BR. 